\title{
Solo Music dengan Penerapan Sistem AKustik
}

\author{
Daniel Yanuar Aditya Beny Prabowo, Suparno, Amin Sumadyo \\ Program Studi Arsitektur \\ Jurusan Arsitektur Fakultas Teknik \\ Universitas Sebelas Maret Surakarta \\ Email : danielguguk@gmail.com
}

\begin{abstract}
Solo's music world is not yet well accousticly contained because Solo does not have any buliding that specifically used for musical activities. The purpose of this design is to create a container of music activities with a good accoustic quality. The problem that emerge is how to design a building to contain music activities with a good accoustic quality. The planned building apply an accoustical system which able to accomodate every music genre with amplified sound. The accoustic room uses many sound absorber for amplified music. The result is music performance building design, music school design, recording studio design, and music studio design with a good accoustic quality.
\end{abstract}

Keywords: Music Performance Building, Music School, Recording Studio, Music Studio, Accoustic System

\section{PENDAHULUAN}

Masyarakat Kota Solo adalah masyarakat yang sangat peduli dengan seni musik. Kepedulian ini dapat dilihat dengan begitu banyaknya acara - acara musik yang ada di kota Solo dengan jumlah penonton yang besar, akan tetapi kota ini tidak memiliki wadah yang mampu menampung kegiatan para seniman musik dan penikmat musik. Selama ini konser musik dilakukan di tempat yang tidak ditujukan untuk penggelaran konser musik seperti stadion, gelanggang olah raga, bekas gedung bioskop dan lain-lain. Kondisi ini tidak memberikan kenyamanan akustik bagi konsumen musik, pemain musik dan produsen musik. Masyarakat musik Solo juga kekurangan tempat untuk berlatih dan belajar musik. Wadah untuk berlatih musik di Solo mayoritas hanya ditujukan untuk menampung musik beraliran populer. Pemusik yang memiliki minat untuk berlatih dan belajar musik dengan aliran lain tidak memiliki wadah untuk berlatih musik yang diminatinya.

Berdasarkan kekurangan wadah tersebut, maka dibutuhkan adanya sebuah pusat musik di Kota Solo yang dapat menampung berbagai macam kegiatan bermusik. Bangunan yang direncanakan diharapkan dapat memenuhi kebutuhan dalam pementasan musik, belajar musik, berlatih musik, produksi musik dan tempat berkumpul bagi para komunitas musik. Perencanaan pusat musik ini dititikberatkan pada kualitas sistem akustik dalam setiap ruangan yang membutuhkan pengolahan akustik.

\section{METODE}

Solo Music merupakan bangunan yang direncanakan untuk menampung berbagai macam kegiatan bermusik. Kendala wadah kegiatan bermusik di Solo adalah buruknya kualitas akustik pada bangunan tersebut. Solo Music mengedepankan sistem akustik terpadu yang mampu menampung segala macam aliran musik baik musik modern maupun musik tradisional atau klasik.

Pementasan musik dikhususkan untuk musik yang menggunakan sistem pengeras suara elektrik. Sistem akustik ruang pementasan dititikberatkan pada kejelasan suara. Kendala utama dalam pementasan musik berepengeras adalah adanya feedback dan pemantulan berkepanjangan (gaung), sehingga untuk mencapai kejelasan suara yang diharapkan perlu dipasang elemen penyerap suara yang lebih dominan pada material penutup dinding.

Kegiatan lain yang ditampung dalam bangunan ini meliputi perekaman musik, 
latihan musik, dan pub. Studio perekaman dan studio latihan membutuhkan perlakuan akustik yang hampir sama karena keduanya merupakan ruangan kecil yang menampung musik dengan volume suara cukup besar. Studio perekaman dan latihan membutuhkan banyak elemen penyerap suara untuk menghindari adanya gaung.

\section{ANALISA}

\subsection{Analisa Peruangan}

Analisa peruangan diperoleh dari analisa kegiatan pengguna bangunan. Adapun kebutuhan ruang bangunan yang direncanakan adalah sebagai berikut.

Tabel 1. Kebutuhan Ruang Pementasan

\begin{tabular}{|l|l|l|}
\hline \multicolumn{1}{|c|}{ Pelaku } & \multicolumn{1}{|c|}{ Kegiatan } & \multicolumn{1}{c|}{$\begin{array}{c}\text { Kebutuhan } \\
\text { Ruang }\end{array}$} \\
\hline 1.a. \\
Pengunjung & $\begin{array}{l}\text { Menonton } \\
\text { pentas duduk }\end{array}$ & $\begin{array}{l}\text { R. Duduk } \\
\text { penonton }\end{array}$ \\
\cline { 2 - 3 } & $\begin{array}{l}\text { Menonton } \\
\text { pentas berdiri }\end{array}$ & $\begin{array}{l}\text { R. Berdiri } \\
\text { penonton }\end{array}$ \\
\hline $\begin{array}{l}\text { 1.b. } \\
\text { Pementas }\end{array}$ & $\begin{array}{l}\text { Berhias dan } \\
\text { ganti baju }\end{array}$ & $\begin{array}{l}\text { R. Ganti dan } \\
\text { rias }\end{array}$ \\
\cline { 2 - 3 } & Pentas & Panggung \\
\hline $\begin{array}{l}\text { 1.c. } \\
\text { Pengelola } \\
\text { pementasan }\end{array}$ & $\begin{array}{l}\text { Mengatur } \\
\text { pencahayaan }\end{array}$ & $\begin{array}{l}\text { R. Kontrol } \\
\text { pencahayaan }\end{array}$ \\
\cline { 2 - 3 } & $\begin{array}{l}\text { Memimpin } \\
\text { pementasan }\end{array}$ & $\begin{array}{l}\text { Ranager } \\
\text { pentas }\end{array}$ \\
\hline
\end{tabular}

Tabel 2. Kebutuhan Ruang Pendukung

\begin{tabular}{|l|l|l|}
\hline $\begin{array}{l}\text { Kelompok } \\
\text { Kegiatan }\end{array}$ & \multicolumn{1}{|c|}{ Kegiatan } & \multicolumn{1}{|c|}{$\begin{array}{c}\text { Kebutuhan } \\
\text { Ruang }\end{array}$} \\
\hline 1.a. Siswa & $\begin{array}{l}\text { Mencari } \\
\text { koleksi buku } \\
\text { atau musik }\end{array}$ & Perpustakaan \\
\cline { 2 - 3 } $\begin{array}{l}\text { Belajar teori } \\
\text { musik }\end{array}$ & R. Teori musik \\
\cline { 2 - 3 } & $\begin{array}{l}\text { Belajar } \\
\text { praktek musik }\end{array}$ & R. Praktek musik \\
\hline 2.Penjualan & $\begin{array}{l}\text { Melihat } \\
\text { koleksi alat } \\
\text { musik }\end{array}$ & $\begin{array}{l}\text { R. Koleksi alat } \\
\text { musik }\end{array}$ \\
\cline { 2 - 3 } & $\begin{array}{l}\text { Menyewa alat } \\
\text { musik }\end{array}$ & $\begin{array}{l}\text { R. Persewaan } \\
\text { alat musik }\end{array}$ \\
\hline $\begin{array}{l}\text { 3.a. } \\
\text { Pengunjung } \\
\text { Perekaman }\end{array}$ & $\begin{array}{l}\text { Pengambilan } \\
\text { sampel }\end{array}$ & $\begin{array}{l}\text { R. Pengambilan } \\
\text { sampel }\end{array}$ \\
\cline { 2 - 3 } & $\begin{array}{l}\text { Pengambilan } \\
\text { suara }\end{array}$ & $\begin{array}{l}\text { Studio } \\
\text { perekaman }\end{array}$ \\
\hline $\begin{array}{l}\text { 4. } \\
\text { Pengunjung } \\
\text { Studio }\end{array}$ & $\begin{array}{l}\text { Berlatih } \\
\text { musik }\end{array}$ & Studio musik \\
\hline
\end{tabular}

\begin{tabular}{|l|l|l|}
\hline $\begin{array}{l}\text { 5.a. } \\
\text { Pengunjung } \\
\text { pub }\end{array}$ & $\begin{array}{l}\text { Makan dan } \\
\text { minum }\end{array}$ & Ruang duduk \\
\cline { 2 - 3 } & Berdansa & Lantai dansa \\
\hline $\begin{array}{l}\text { 5.b. } \\
\text { Pementas } \\
\text { pub }\end{array}$ & Pentas & Panggung \\
\hline
\end{tabular}

\subsection{Analisa Ruang Akustik}

\subsubsection{Ruang Pementasan}

Kebutuhan akustik untuk gedung pementasan yaitu:

1. Tingkat kekerasan yang merata pada seluruh bagian ruangan.

Ruangan membutuhkan speaker yang diposisikan pada beberapa bagian ruang, karena suara dari speaker utama melemah pada jarak 14 meter yang diletakkan seperti pada Gambar 1.

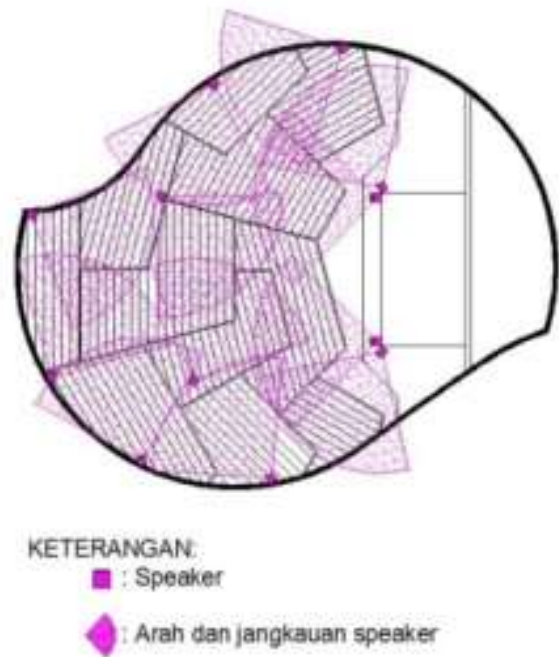

Gambar 1. Perletakan Speaker dalam Ruang Pementasan

2. Bebas dari cacat akustik.

Menurut Leslie (1985), untuk mencegah cacat akustik, diperlukan dinding pembias suara dan beberapa panel yang digunakan untuk menyerap suara yang diposisikan seperti gambar berikut: 


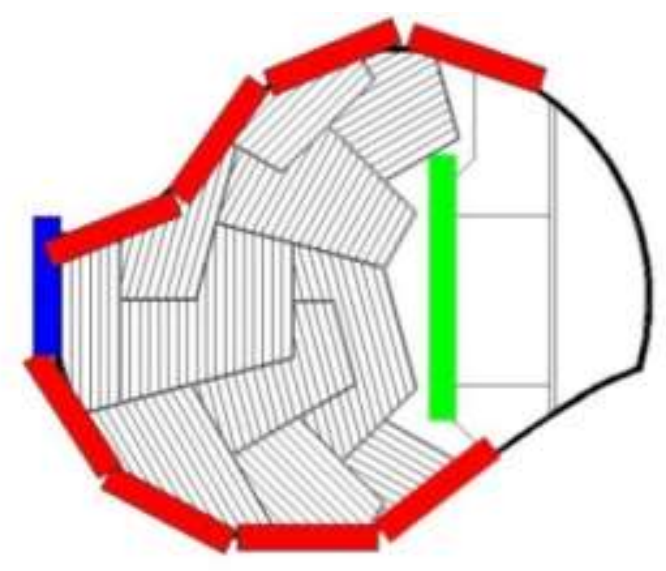

KETERANGAN:

Elemen Pendifusi

Elemen Penyerap

Elemen Pemantul

Gambar 2. Perletakan Elemen Akustik

3. Waktu dengung sekitar 1,8 detik.

Syarat waktu dengung digunakan untuk menentukan jenis dinding ruangan.

$$
\text { RT60 = }(0,161 \times \text { V) / (A x S })
$$

1) Luasan dari lantai penonton adalah $1200 \mathrm{~m}^{2}$.

2) RT ditentukan 1,8 detik

3) Koefisien serap dipilih antara kayu $(0,1)$, karpet $(0,14)$, gypsum $(0,05)$, dan panel penyerap $(0,25)$.

$$
\begin{aligned}
& 1,8=(0,161 \times(\mathrm{p} \times 1 \times \mathrm{t}) /(((2 \times \mathrm{p} \times 1) \\
& +(2 \times \mathrm{p} \times \mathrm{t})+(2 \times 1 \times \mathrm{t})) \times 0,35) \\
& \mathrm{S}=0,28
\end{aligned}
$$

Berdasarkan hasil perhitungan di atas, elemen yang digunakan adalah panel penyerap.

4. Difusi bunyi merata.

Difusi bunyi dioptimalkan dengan plafond berbentuk bergerigi dengan bidang gerigi mengarah kepada penonton. Bahan plafond menggunakan gypsum yang bersifat memantul (lihat Gambar 3 dan 4).

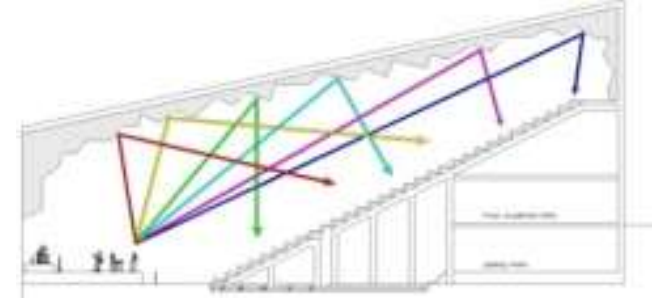

Gambar 3. Pola Pemantulan Vertikal

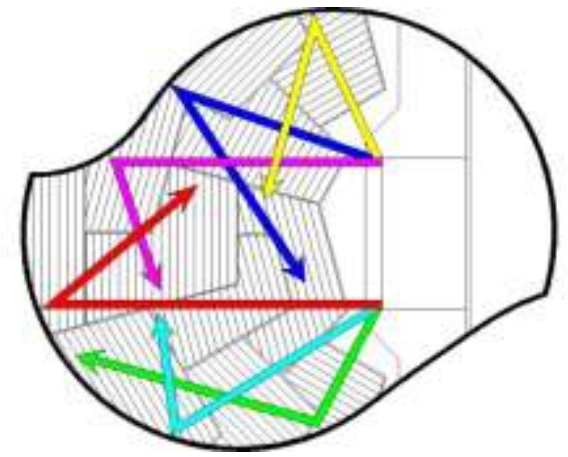

Gambar 4. Pola Pemantulan Horizontal

5. Tidak ada gangguan feedback.

Untuk menghindari terjadinya feedback diperlukan panel pemantul dan penyerap suara pada bagian panggung.

6. Bebas dari gangguan suara yang berasal dari luar ruangan.

Menurut De Chiara (1980) untuk meminimalisir gangguan suara dari luar, diperlukan beberapa langkah berikut:

a. Memisahkan bangunan dengan fungsi yang berbeda.

b. Menempatkan peralatan utilitas bangunan jauh dari ruang akustik.

c. Melapisi sela - sela kusen pintu dengan bahan khusus.

d. Saluran udara tidak dilewatkan pada daerah dengan kebisingan tinggi.

\subsubsection{Ruang Perekaman}

Kebutuhan akustik untuk ruang perekaman yaitu:

a. Tidak terjadi feedback.

Speaker tidak diarahkan ke bidang pantul apapun. Arah pemain musik tidak boleh mengarah pada speaker secara langsung.

b. Meminimalisir pemantulan.

Pemantulan suara dalam ruangan dikurangi dengan memperbanyak material pelapis suara. Semua bagian dinding, langit - langit, dan lantai dilapisi dengan material penyerap suara.

c. Warna suara kering.

Warna suara yang kering diperoleh dengan pemasangan beberapa material khusus penyerap suara yang diletakkan pada sudut ruangan.

d. Bebas gangguan suara dari luar ruangan. Untuk menghindari gangguan suara dari luar, maka perlu dipasang pintu dan jendela dengan bahan pelapis sekat. Kabel dibungkus dengan bahan insulator bunyi seperti isolasi dan busa. 
Selain beberapa hal tersebut, terdapat 2 macam ruangan yang khusus digunakan untuk merekam suara elektrik dan suara asli.

1. Perekaman Instrumen Elektrik

Ruang perekaman instrumen elektrik menggunakan bahan pelapis ruang dengan daya serap tinggi. Bahan pelapis terluar yang digunakan adalah glasswool dan karpet tebal seperti pada Gambar 5 di bawah ini:

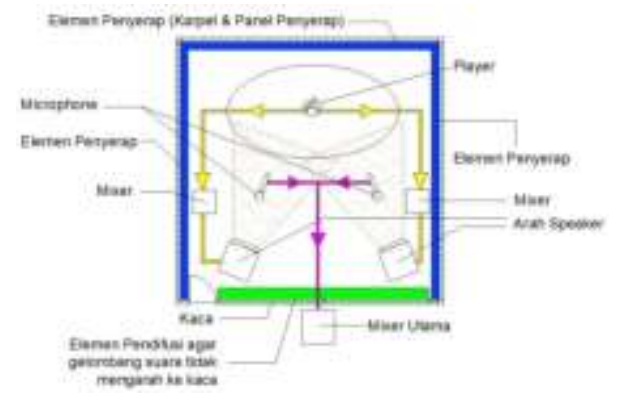

Gambar 5. Layout Studio Perekaman Elektrik

2. Perekaman Instrumen Mekanik

Ruang perekaman instrumen mekanik menggunakan campuran antara bahan penyerap dan pemantul untuk mendapatkan efek room ketika suara direkam (lihat Gambar 6). Bahan yang digunakan adalah kayu lapis yang bersifat tidak terlalu menyerap suara.

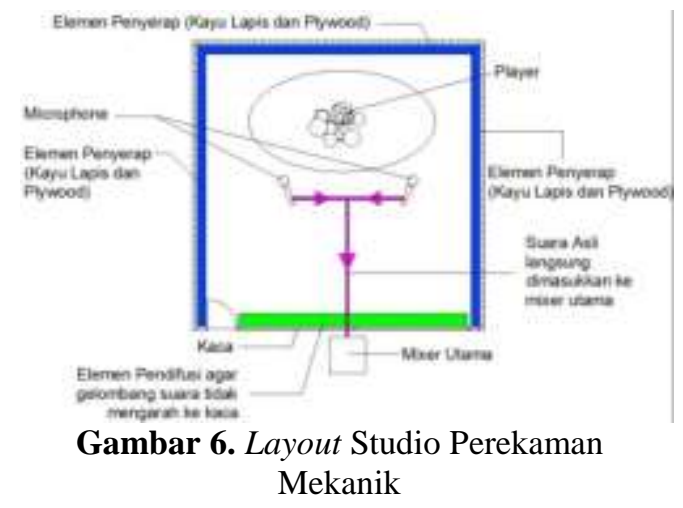

\subsubsection{Studio Musik}

Terdapat 2 jenis ruangan dalam studio musik, yaitu studio musik elektrik dan studio musik klasik.

\subsubsection{Studio Musik Elektrik}

Studio musik elektrik tidak menggunakan bahan pemantul suara maupun penyebar suara untuk menghindari gaung tambahan (lihat Gambar 7). Penanganan akustikal lebih dititikberatkan pada penyerapan suara.

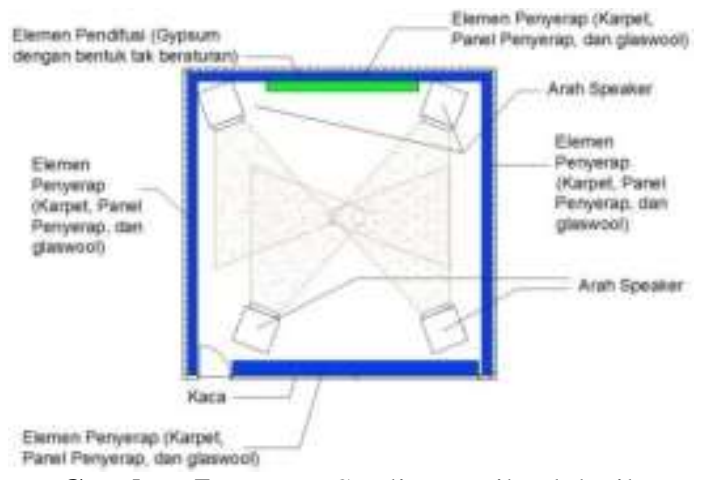

Gambar 7. Layout Studio Musik Elektrik

\subsubsection{Studio Musik Klasik}

Studio musik klasik menempati ruangan yang cukup luas karena digunakan pengguna yang berjumlah banyak. Studio musik klasik membutuhkan elemen pemantul dan pembias suara (lihat Gambar 8). Elemen pembias dan pemantul suara dipasang pada dinding dan plafond ruangan.

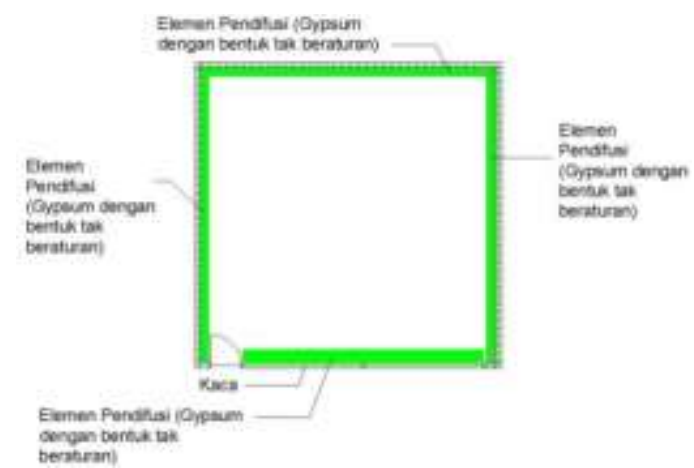

Gambar 8. Perletakan Elemen Akustik Pada Studio Musik Klasik

\subsubsection{Pub}

Ruangan $p u b$ digunakan untuk menampung musik berpengeras. Ruangan memiliki karakter musik yang mengutamakan kejelasan suara berfrekuensi rendah seperti bass dan cello. Berikut merupakan ketentuan - ketentuan akustik untuk ruangan $p u b$.

1. Meminimalisir Gaung dan Gema

Untuk meminimalisir gaung dan gema maka diperlukan banyak elemen penyerap suara yang dipasang pada dinding dan plafond ruang (lihat Gambar 9). Lantai ruangan dibuat dari material penyerap suara yang memiliki lapisan dan material yang sama dengan lantai ruang pementasan. Koefisien serap pelapis ruangan harus memiliki besaran yang sama dengan koefisien serap tubuh 
manusia, sehingga ruangan bisa menampung pengguna dengan jumlah besar maupun kecil.

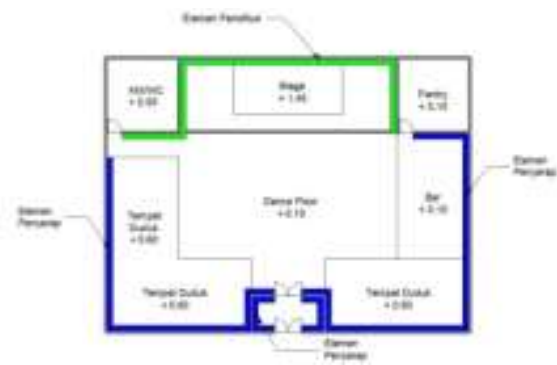

Gambar 9. Layout Elemen Akustik pada Ruang $P u b$

2. Suara tidak bocor ke luar maupun ke dalam

Pengisolasian suara pada ruang pub diterapkan melalui pemberian ruang transisi pada setiap pintu masuk ruangan. Setiap kusen jendela dan pintu diberi seal insulator yang mampu menahan suara.

3. Kualitas suara sama dalam kondisi penuh atau kosong

Unsur - unsur pelapis ruangan harus memiliki tingkat serap suara yang sama dengan manusia. Elemen akustik yang memiliki tingkat serap suara yang lebih tinggi dari manusia adalah busa, dan yang setingkat lebih rendah adalah kayu. Untuk mencapai keseragaman suara, kayu dan busa dipergunakan sebagai pembentuk material ruangan.

\subsection{Analisis Lokasi}

1. Tujuan:

Mendapatkan lokasi yang sesuai dengan bangunan yang direncanakan.

2. Dasar pertimbangan:

Posisi tapak strategis untuk ekspos tampilan fisik bangunan, luasan tapak dapat menampung seluruh kebutuhan ruang yang direncanakan, lokasi tapak sesuai dengan RUTRK Kota Surakarta.

3. Proses Analisis:

Terdapat 4 alternatif dalam pemilihan lokasi tapak yaitu Asrama Polri Manahan, Kawasan Kota Barat, Kawasan Gendengan, dan Kawasan Ngarsopuro. Kawasan Ngarsopuro dipilih karena mencukupi dalam segala pertimbangan yang ada.

\subsection{Analisis Pencapaian}

1. Tujuan:
Menentukan main entrance, side entrance, dan service entrance.

2. Dasar Pertimbangan:

a. Kemudahan dalam mencapai tapak.

b. Kemanan dalam mencapai tapak.

c. Jenis kelompok kegiatan dan pengguna.

d. Penyesuaian kondisi lalu litas sekitar.

3. Proses Analisis (lihat Gambar 10):

a. Main Entrance

Ditempatkan pada Jl. Slamet Riyadi, karena merupakan jalur terbesar.

b. Side Entrance

Ditempatkan pada Jl. Diponegoro dengan tujuan menarik masyarakat yang berada di Koridor Ngarsopuro.

c. Service Entrance

Ditempatkan pada Jl. Madura agar tidak mengganggu lalu lintas sekitar dan jalan utama masuk bangunan.

d. Exit Point

Ditempatkan pada Jl. Kartini dengan karena jalan ini merupakan jalan 2 arah dan tidak terlalu ramai.

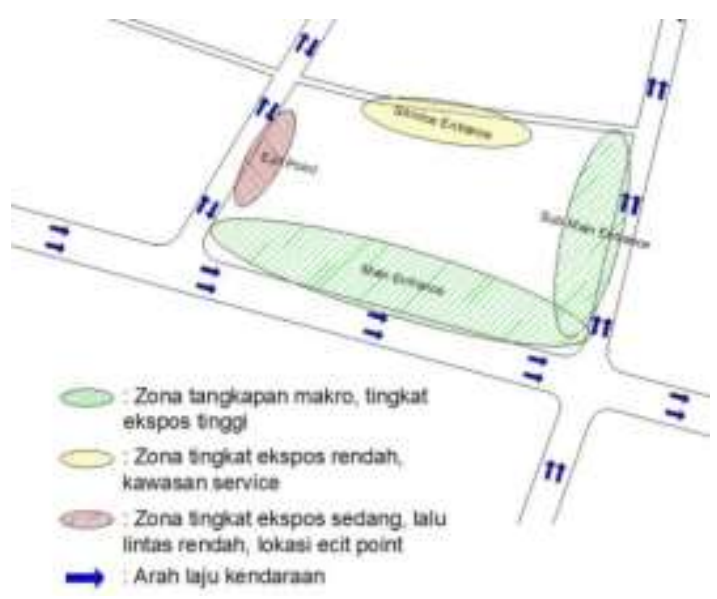

Gambar 10. Perletakan Jalur Masuk ke dalam Tapak

\subsection{Analisis Orientasi Bangunan}

1. Tujuan

Mendapatkan arah orientasi bangunan untuk memaksimalkan tingkat ekspos bangunan.

2. Dasar Pertimbangan

Sudut pandang dari arah luar bangunan menuju tapak, kondisi lingkungan sekitar, tampilan menarik secara komersial.

3. Proses Analisis

Orientasi utama bangunan mengarah ke Jl. Slamet Riyadi dan pertigaan antara Jl. Slamet Riyadi dan Jl. Diponegoro. 
Orientasi sekunder berada pada sisi yang menghadap Jl. Diponegoro untuk keperluan komersial.

\subsection{Analisis Penangan Kebisingan}

1. Tujuan

Mendapatkan sistem pengurangan kebisingan yang bersumber dari luar tapak.

2. Dasar Pertimbangan

Kelompok kegiatan pagelaran, perekaman dan pendidikan musik membutuhkan tingkat bising yang rendah.

3. Proses Analisa

Daerah penghasil kebisingan utama adalah Jl. Slamet Riyadi. Daerah Koridor Ngarsopuro memiliki tingkat kebisingan sedang. Daerah Jl. Kartini dan Jl. Madura mempunyai tingkat bising terendah. Vegetasi digunakan untuk menghalangi suara bising (lihat Gambar 11).

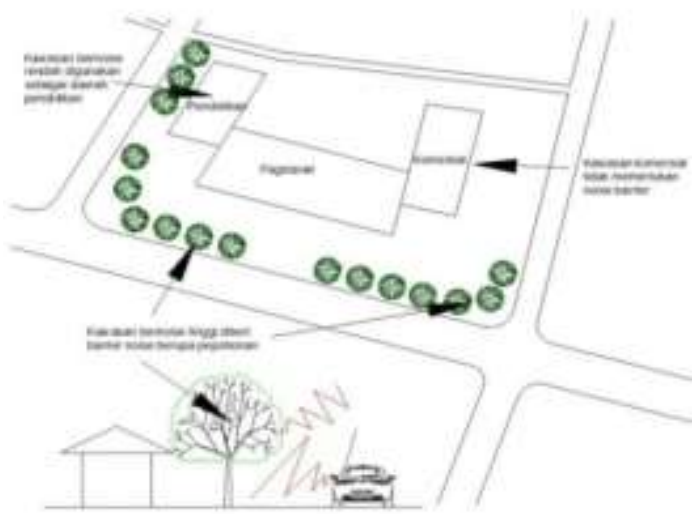

Gambar 11. Penanganan Kebisingan

\subsection{Analisis Pemintakatan}

1. Tujuan

Menentukan mintakat berdasarkan sifat kegiatan dan keadaan pada tapak.

2. Dasar pertimbangan

Analisis peruangan, analisis pengolahan tapak, analisis struktur.

3. Proses analisis

Menggabungkan persyaratan ruang, berdasarkan kelompok kegiatan dan analisis pengolahan tapak dengan hasil seperti Gambar 12.

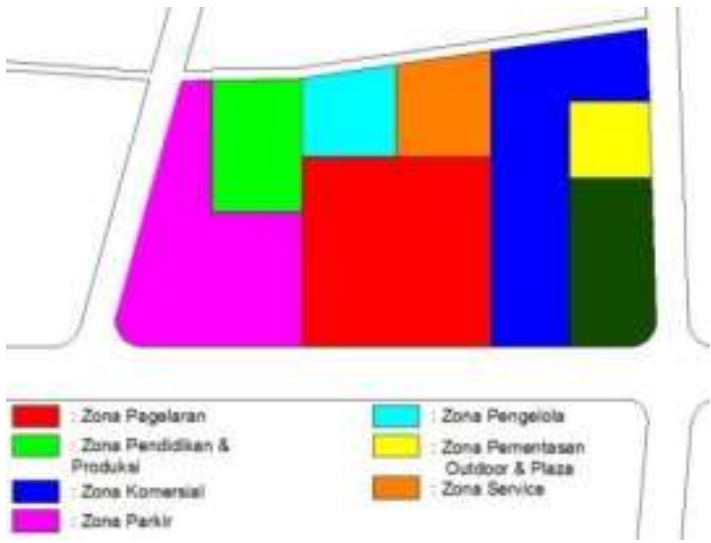

Gambar 12. Pemintakatan

\subsection{Analisis Bentuk dan Tampilan Bangunan}

\subsubsection{Bentuk Dasar Bangunan}

Terdapat 3 pemikiran dasar dalam penentuan bentuk dasar bangunan, yaitu:

1. Menurut teori DK. Ching (1979), terdapat 3 jenis bentuk dasar, yaitu segi tiga, segi empat, dan lingkaran. Bangunan yang direncanakan mengambil bentuk lingkaran.

2. Bentuk bangunan berdasarkan tiruan alam.

3. Bentuk bangunan disesuaikan dengan konteks kegiatan bangunan.

\subsubsection{Karakter Bangunan}

Bangunan yang direncanakan harus bersifat atraktif dan ekspresif.

\subsubsection{Atraktif}

Sifat atraktif bangunan didapat dengan penggunaan bentuk lengkung agar berbeda dengan bangunan di sekitarnya.

\subsubsection{Ekspresif}

Untuk memunculkan sifat ekspresif bangunan, not balok digunakan dalam pembentukan wujud bangunan.

\subsubsection{Gubahan Tata Massa}

\subsubsection{Tata Massa Horizontal}

Penataan tata massa bangunan menggunakan kaidah kesatuan, pengulangan dan tema. Penataan massa bangunan mengambil dari tiruan alam, yaitu tangkai bunga (lihat Gambar 13). 


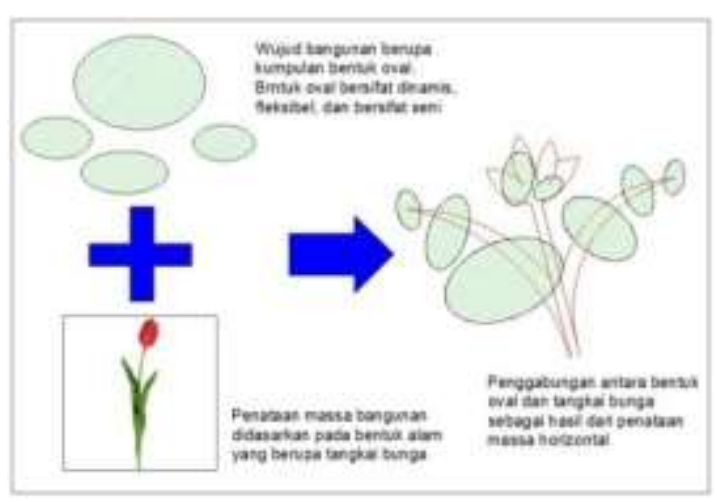

Gambar 13. Tata Massa Horizontal

\subsubsection{Tata Massa Vertikal}

Bangunan menggunakan wujud not balok. Bentuk not balok merupakan simbol yang kuat dalam representasi musik dalam bangunan. Selain not balok, bangunan juga memiliki elemen berupa lengkungan menggambarkan suasana musik yang mengalun (lihat Gambar 14)

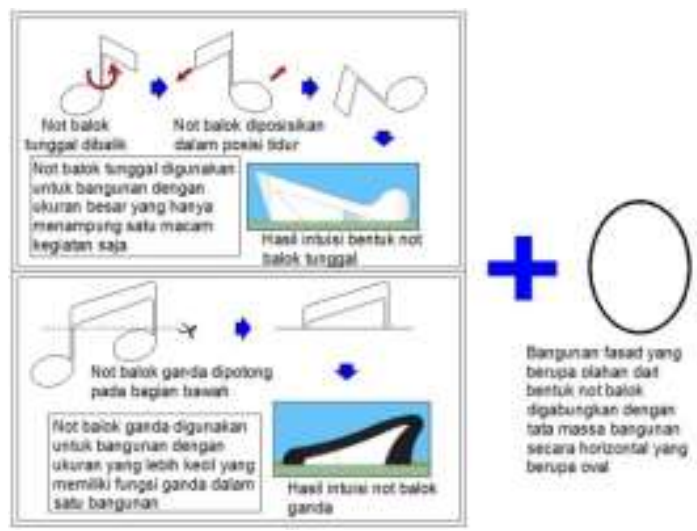

Gambar 14. Tata Massa Vertikal

\subsubsection{Perletakan Bangunan dalam Tapak (lihat Gambar 15)}

Dasar pertimbangan yang digunakan antara lain:

1. Berdasarkan arah dan orientasi bangunan.

2. Berdasarkan bentuk dan tata massa bangunan.

3. Hasil analisis perancangan tapak.

4. Hasil analisis konsep dasar dan karakter bangunan.

5. Peraturan yang ada.

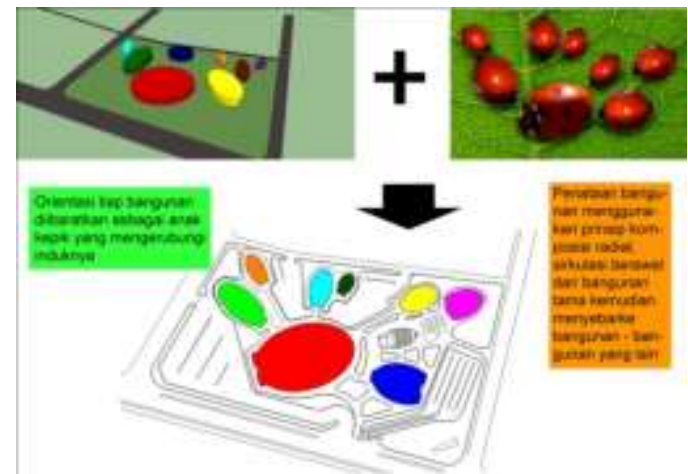

Gambar 15. Perletakan Bangunan dalam Tapak

\section{KESIMPULAN}

Dari hasil analisa serta hasil korelasi pada bagian sebelumnya, maka diperoleh hasil berupa desain Solo Music dengan sistem akustik yang mengedepankan kejelasan suara untuk dapat digunakan oleh berbagai macam aliran musik. Bentuk ruangan pementasan musik dirancang untuk memantulkan suara ke segala arah dengan bentuk yang tidak simetris (lihat Gambar 16 dan 17), serta penggunaan bahan pelapis ruang berupa kayu, busa, dan panel penyerap sebagai elemen penyerap suara dan gypsum sebagai elemen pemantul dan pembias. Ruangan studio perekaman dan studio latihan menggunakan banyak penyerapan suara dengan karpet tebal, busa dan panel penyerap untuk mengatasi pemantulan berkepanjangan dalam ruangan yang sempit dengan volume suara yang besar (lihat Gambar 18 dan Gambar 19). Pub mengedepankan peredaman suara yang didominasi oleh suara berfrekuensi rendah agar tetap nyaman didengarkan dan tidak bocor ke luar.

Adapun detail bangunan yang direncanakan adalah sebagai berikut :

Nama Bangunan : Solo Music

Lokasi : Jl. Slamet Riyadi

Luas Lahan $\quad: 15.052,45 \mathrm{~m}^{2}$

Luas Bangunan $\quad: 4.462,72 \mathrm{~m}^{2}$

Jumlah Pengguna : 3.000 orang

Kegiatan : Musik

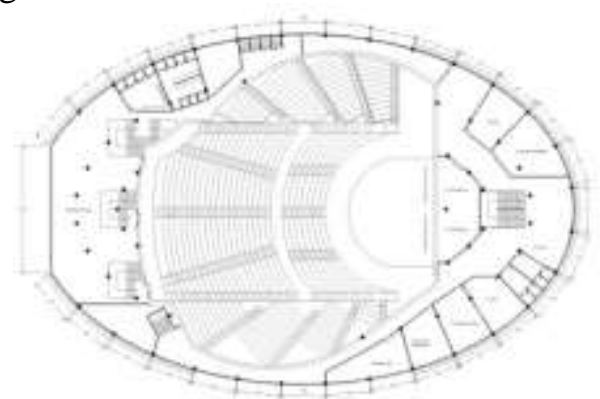

Gambar 16. Denah Gedung Pementasan 


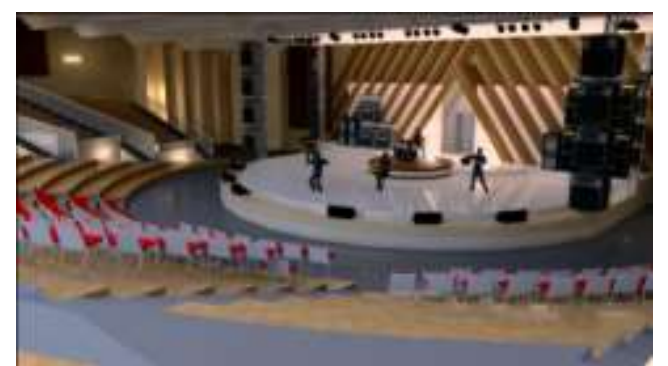

Gambar 17. Desain Interior dan Elemen Akustik pada Ruang Pementasan

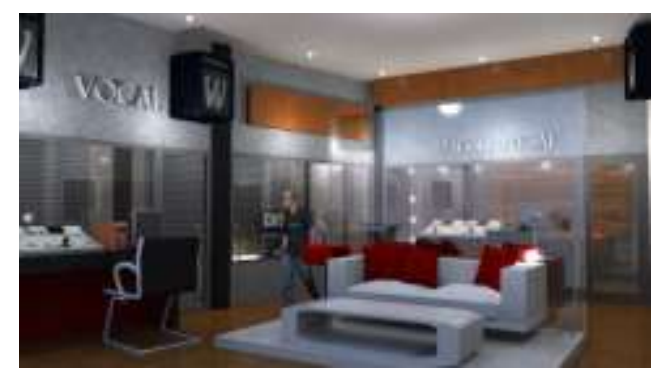

Gambar 18. Desain Interior dan Pemasangan Elemen Akustik pada Studio Perekaman

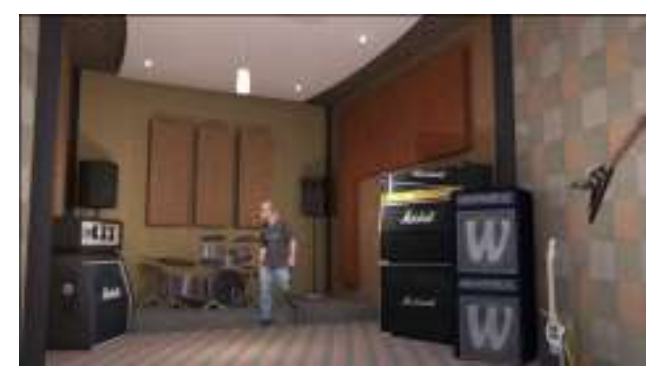

Gambar 19. Desain Interior dan Pemasangan Elemen Akustik pada Studio Latihan

\section{REFERENSI}

De Chiara, Joseph, John Hancock, 1980, Time Saver Standart for Building Types (sixth edition)

D.K. Ching, Francis, 1979, Arsitektur, Bentuk Ruang dan Susunannya

Leslie L. Doelle, Eng., M.Arch., 1985, Akustik Lingkungan, Penerbit Erlangga, Surabaya 